\title{
Use of histological examination to assess ultrastructure of liver in patients with long standing jejuno-ileal bypass for morbid obesity
}

\author{
A P BOON, * H THOMPSON, $\uparrow$ R M BADDELEY $\ddagger$ \\ From the *Department of Pathology, Medical School, University of Birmingham, and the Departments of \\ $\dagger$ Pathology and $\ddagger$ Surgery, General Hospital, Birmingham
}

SUMMARY To assess the pattern and severity of liver disease in patients who had undergone jejunoileal bypass for the treatment of morbid obesity, 23 patients were biopsied, all of whom had had intact bypasses for more than 10 years. These were examined by light and electron microscopy. Previous biopsy specimens from each patient, including specimens taken before bypass, were reviewed. Similar biopsy specimens were obtained from six obese patients undergoing gastroplasty. There was no evidence of cirrhosis, and mild or moderate degrees of fibrosis were found in only a few patients. Steatosis tended to persist after bypass, albeit to a lesser degree. Giant mitochondria and intramitochondrial filamentous inclusions were present in four of six specimens taken before gastroplasty and in 15 of 23 specimens taken after jejuno-ileal bypass, being especially numerous in those specimens showing little or no steatosis.

It is suggested that such features reflect ultrastructural evidence of adaptation to an abnormal metabolic environment both in the morbidly obese and even many years after jejuno-ileal bypass. Their prognostic importance is unclear.

Jejuno-ileal bypass procedures were for many years the most popular approach in the surgical treatment of morbid obesity. Since the pioneering work of Payne and Dewind ${ }^{1}$ it has been estimated ${ }^{2}$ that more than 100000 patients worldwide have undergone intestinal bypass. Although a successful means of weight reduction, it soon became apparent that several serious and possibly fatal side-effects could occur. ${ }^{3-5}$ Of the many complications described following jejuno-ileal bypass, one of the most important is the insidious development of hepatic fibrosis and cirrhosis in up to $10 \%$ of cases. ${ }^{6-9}$ As a consequence this operation has now fallen out of favour except in rare and selected cases. ${ }^{10}$ "Many patients remain, however, with intact and apparently successful bypasses. Their future management is a formidable clinical problem.

It is recognised that biochemical tests of liver function are unreliable in detecting slowly progressive hepatic fibrosis. ${ }^{12}$ Follow up by liver biopsy on a routine basis has therefore been widely recommended, but it is unclear whether this should be carried out

Accepted for publication 23 June 1988 indefinitely or whether the risk of hepatic damage eventually diminishes. The aim of this study, therefore, was to determine the pattern and extent of morphological liver abnormalities in a group of patients with jejuno-ileal bypasses that had remained intact for more than 10 years. Ultrastructural abnormalities have previously been reported in a short term follow up study, ${ }^{13}$ and we were particularly interested to discover whether these persist or ultimately resolve.

\section{Material and methods}

Needle biopsy specimens of liver were obtained from 23 patients ( 21 female, two male, mean age 46 years), who had undergone clinically successful "end-to-side" jejuno-ileal bypass procedures a mean of 11.4 years (range 10-13) previously ("bypass group"). Patients were selected as part of a routine follow up and were a representative subset. To provide a baseline comparison of ultrastructural features similar biopsy specimens were obtained from six morbidly obese patients (all female) mean age 38 years, undergoing gastroplasty as a primary procedure ("pre-gastroplasty" group). All patients underwent full pre- 
operative clinical, biochemical, and haematological assessment. None was taking potentially hepatotoxic medications. Two of the pre-gastroplasty group and four of the bypass group showed a mild to moderate increase in serum aspartate transaminase (AST): 33 and $137 \mathrm{U} / 1$ and $33,38,42$ and $59 \mathrm{U} / 1$, respectively (adult reference intervals $=5-31 \mathrm{U} / \mathrm{l}$ ). Other variables were normal. None of the patients was overtly diabetic and none admitted to excess alcohol consumption. The reliability of this latter information in these patients is, however, regarded as doubtful. ${ }^{14}$ Mean weight loss in the bypass group was $48 \mathrm{~kg}$ (37\%), a figure typical of previous series. ${ }^{315} 16$

Immediately after removal several $1 \mathrm{~mm}$ blocks of liver were placed in chilled $\left(4^{\circ} \mathrm{C}\right) 5 \%$ glutaraldehyde in $0.1 \mathrm{M}$ cacodylate buffer at $\mathrm{pH} 7.4$ for two hours. Tissue was post-fixed in $1 \%$ osmium tetroxide in sucrose buffer for one hour at room temperature, dehydrated in a graded series of alcohols, and embedded in Emix resin. (Emscope Laboratories Limited, Ashford, Kent). Semithin sections (0.5-1.0 $\mu \mathrm{m})$ were prepared for light microscopy and stained with toluidine blue. Thin sections $(90 \mathrm{~nm})$ were double stained with uranyl acetate and lead citrate, mounted on $100 \mu \mathrm{m}$ copper mesh grids, and examined using a Philips 201 electron microscope. Photomicrographs of specific ultrastructural features including hepatocyte mitochondria, fat-storing (Ito) cells, and perisinusoidal collagen fibres were prepared. Each of these was assessed semiquantitatively $(0,1+, 2+$ and $3+)$ according to prevalence of abnormal forms, extent of development of rough endoplasmic reticulum, and deposition of collagen fibres within the space of Disse, respectively.

The remainder of each biopsy specimen was fixed in $10 \%$ neutral buffered formalin at room temperature, routinely processed, and embedded in paraffin wax blocks. Sections $(5 \mu \mathrm{m})$ were prepared for light microscopic examination, and stained with haematoxylin and eosin, haematoxylin Van Geison, and a reticulin method.

Preoperative wedge biopsy specimens from all but one of the bypass patients were available in file embedded in paraffin wax blocks. Fresh $5 \mu \mathrm{m}$ sections stained with haematoxylin Van Geison were prepared and examined from each biopsy specimen. All biopsy specimens were assessed semiquantitatively for degree of steatosis, fibrosis, and inflammation: $0=$ absent/ minimal, $1+=$ mild $(<25 \%$ hepatocytes contain fat droplets), $2+=$ moderate $(25-50 \%$ steatosis), $3+=$ severe ( $>50 \%$ steatosis).

\section{Results}

\section{LIGHT MICROSCOPIC FINDINGS}

Five of six pre-gastroplasty biopsy specimens showed only mild steatosis with no other obvious abnormalities (table). The remaining biopsy specimen showed features indistinguishable from alcoholic hepatitis with moderate fibrosis, although Mallory's hyalin was not evident. Appearance was consistent with so-callede․ non-alcoholic steatohepatitis.

None of the bypass biopsy specimens showed evidence of cirrhosis. Lipogranulomas were present in

Table Morphological data

\begin{tabular}{|c|c|c|c|c|}
\hline & & \multirow[b]{2}{*}{$\begin{array}{l}\text { Pre-gastroplasty } \\
\text { group }(n=6)\end{array}$} & \multicolumn{2}{|l|}{ Bypass group } \\
\hline & & & $\begin{array}{l}\text { Preoperative biopsy } \\
(n=22)\end{array}$ & $\begin{array}{l}\text { Current biopsy } \\
(n=23)\end{array}$ \\
\hline Steatosis: & $\begin{array}{l}0 \text { (None/minimal) } \\
1+\text { (Mild) } \\
2+\text { (Moderate) } \\
3+\text { (Severe) }\end{array}$ & $\begin{array}{l}2 \\
3 \\
0 \\
1\end{array}$ & $\begin{array}{r}1 \\
12 \\
4 \\
5\end{array}$ & $\begin{array}{r}5 \\
12 \\
3 \\
3\end{array}$ \\
\hline Fibrosis: & $\begin{array}{l}0 \quad \text { (None/minimal) } \\
1+\text { (Mild) } \\
2+\text { (Moderate) } \\
3+\text { (Severe) }\end{array}$ & $\begin{array}{l}5 \\
0 \\
1 \\
0\end{array}$ & $\begin{array}{r}18 \\
4 \\
0 \\
0\end{array}$ & $\begin{array}{r}16 \\
5 \\
2 \\
0\end{array}$ \\
\hline Inflammation: & $\begin{array}{l}0 \text { (None/minimal) } \\
1+\text { (Mild) } \\
2+\text { (Moderate) } \\
3+\text { (Severe) }\end{array}$ & $\begin{array}{l}5 \\
0 \\
1 \\
0\end{array}$ & $\begin{array}{r}15 \\
7 \\
0 \\
0\end{array}$ & $\begin{array}{r}17 \\
6 \\
0 \\
0\end{array}$ \\
\hline Giant mitochondria: & $\begin{array}{l}0 \quad \text { (None) } \\
1+\text { (Oocasional) } \\
2+\text { (Moderate Nos) } \\
3+(\text { Common })\end{array}$ & $\begin{array}{l}2 \\
1 \\
1 \\
2\end{array}$ & $\bar{E}$ & $\begin{array}{r}10 \\
9 \\
1 \\
3\end{array}$ \\
\hline $\begin{array}{l}\text { Rough endoplasmic } \\
\text { reticulum in fat-storing } \\
\text { cells }\end{array}$ & $\begin{array}{l}0 \quad \text { (Inconspicuous) } \\
1+\text { (Recognisable) } \\
2+\text { (Prominent) } \\
3+\text { (Abundant) }\end{array}$ & $\begin{array}{l}5 \\
1 \\
0 \\
0\end{array}$ & $\frac{-}{-}$ & $\begin{array}{r}12 \\
11 \\
0 \\
0\end{array}$ \\
\hline
\end{tabular}




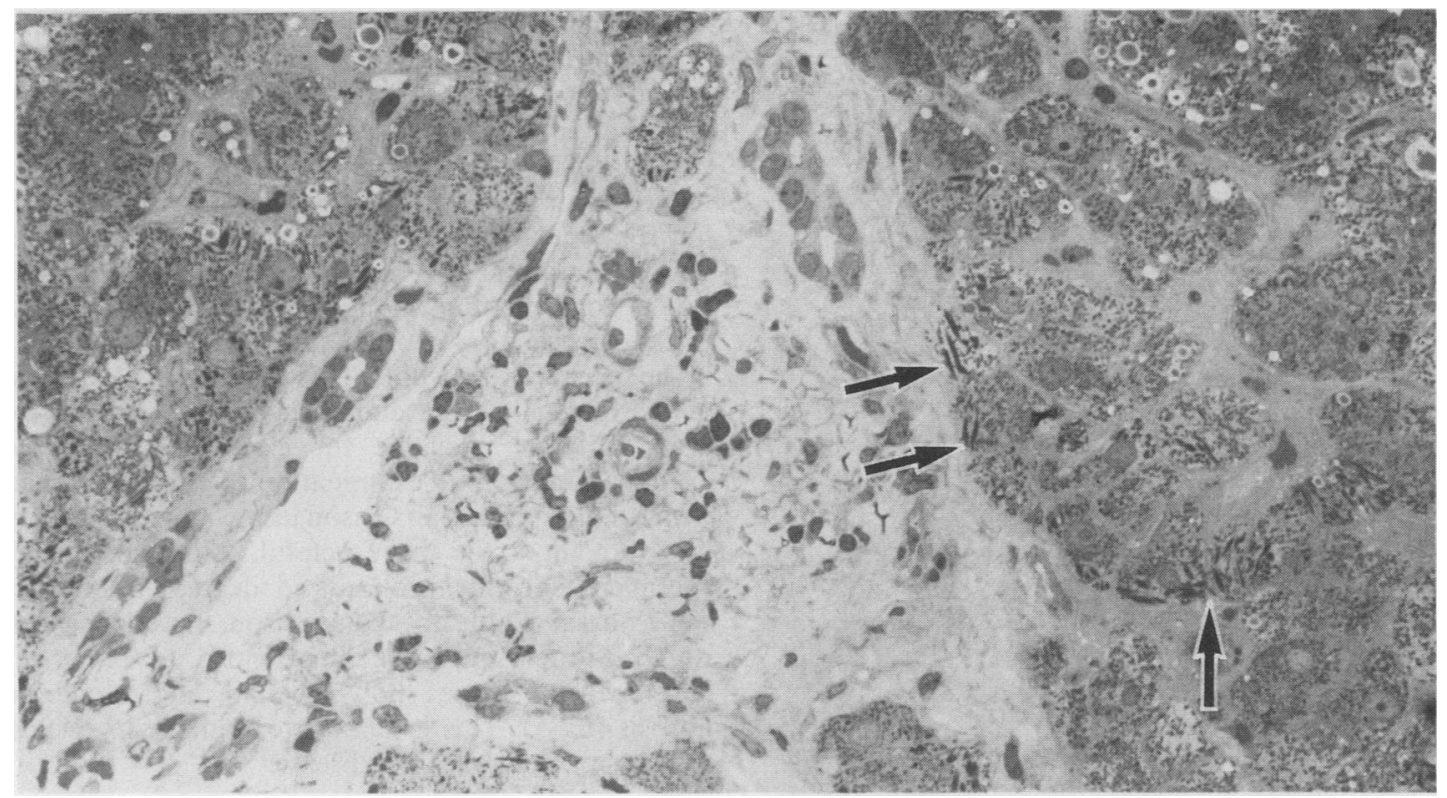

Fig 1 Periportal hepatocytes containing giant mitochondria (arrows). (Toluidine blue.)

eight of $23(35 \%)$ current biopsy specimens but none was of epithelioid type. Steatosis was present in 18 (78\%) current biopsy specimens compared with 21 of $22(95 \%)$ specimens before bypass (table). Mild to moderate pericentral fibrosis with or without a degree of portal fibrosis was noted in seven of $23(30 \%)$ current specimens but in only four of $22(17 \%)$ before bypass, in all of which this was mild and pericentral. A slight excess of portal chronic inflammatory cells was present in six (26\%) of the current specimens, accompanied by mild lobular inflammatory features in two cases.

In the absence of obvious inflammation there was no direct correlation between degree of fibrosis or steatosis and an increase in serum AST.

Semithin sections were examined for orientation of electron microscope sections. In all cases orientation within the lobule was achieved by identification of either a portal area or central venule, or both. In addition to features noted in $5 \mu \mathrm{m}$ sections, abnormally enlarged or bizarre mitochondria (giant mitochondria) were evident in a high proportion of specimens, appearing as dense irregular or needle shaped inclusions (fig 1). These were predominantly within periportal hepatocytes.

\section{ELECTRON MICROSCOPIC FINDINGS}

Giant mitochondria, invariably associated with intramitochondrial filamentous inclusions or crystalloids, were noted in four of six pre-gastroplasty and in 13 of 23 bypass biopsy specimens (table). These were generally narrow and elongated (type II as defined by Uchida et al $^{17}$ ). Occasional giant mitochondria of irregular morphology (type III) were found (fig 2). Spherical (type I) mitochondria, said to be typical of alcoholic liver disease, ${ }^{17}$ were not seen. As noted in semithin sections under light microscopy, giant mitochondria were most common in periportal hepatocytes. At high magnification intramitochondrial filamentous inclusions were usually orientated with their long axis parallel to the longitudinal axis of the mitochondrion (fig 3). In several cases parallel rows of mitochondrial cristae were aligned at an angle of about $45^{\circ}$ to the intramitochondrial filamentous inclusion (arrows). These and other features are very similar to those noted by Friedman et al. ${ }^{13}$ The prevalence of giant mitochondria within each thin section was assessed semiquantitatively 0 to $3+$ and related to the degree of steatosis within the whole biopsy specimen as seen under light microscopy (fig 4). It is noteworthy that moderate to large numbers of giant mitochondria were present only in those specimens showing little or no steatosis. Conversely, in moderately or very fatty livers giant mitochondria were either absent or seen only occasionally. Owing to the small numbers involved, this correlation does not reach the level of significance. (The one exception to the general trend was the single pre-gastroplasty biopsy specimen showing steatohepatitis.) There was no apparent correlation between numbers of giant 


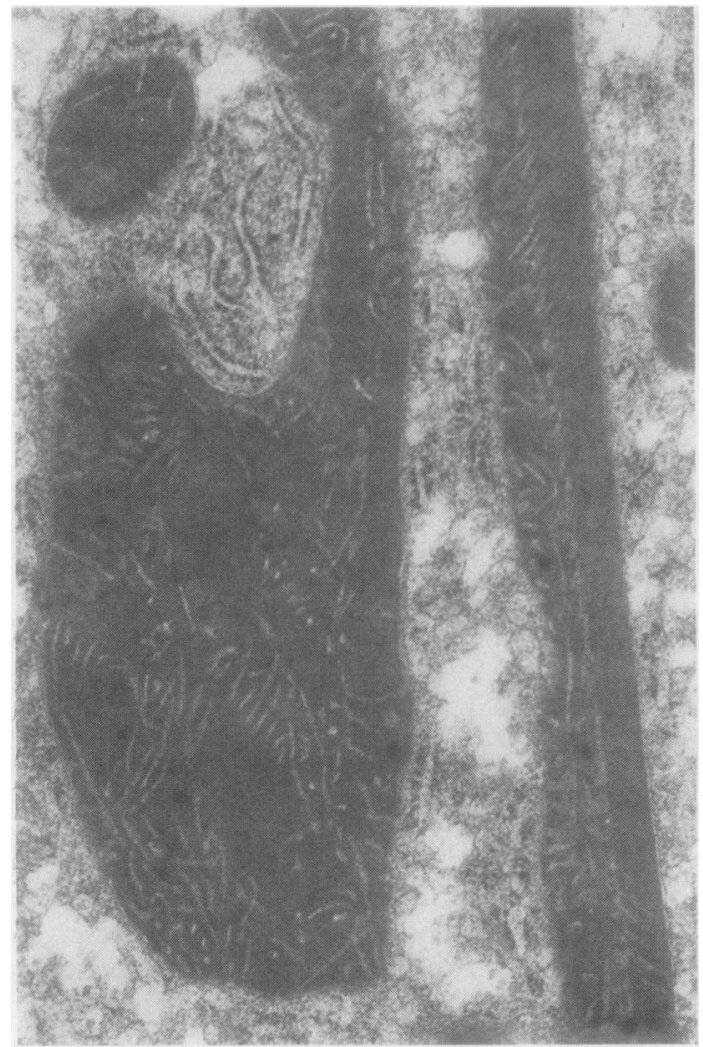

Fig 2 Irregular giant mitochondria (type III). mitochondria and an increase in serum AST, degree of fibrosis, or the presence of inflammation.

Fat-storing (Ito) cells were found with varying degree of difficulty in all sections. The extent of rough endoplasmic reticulum development was assessed semiquantitatively 0 to $3+$ and related to the degree of fibrosis occurring in the biopsy specimen as a whole. Unlike Minato et al, ${ }^{18}$ electron microscopic examination of collagen fibres in the space of Disse was found to be unsatisfactory in predicting the extent of fibrosis in the specimen as a whole. This may be a consequence of the relatively small and perhaps unrepresentative area of tissue available for electron microscopic examination. Careful examination of sections stained with haematoxylin Van Gieson using light microscopy was thought to be more helpful. Although biopsy specimens showing pronounced degrees of fibrosis were not available for comparison, fat-storing cell rough endoplasmic reticulum tended to be better developed in those showing mild and moderate fibrosis (fig 5). This is similar to findings in certain patterns of alcoholic liver disease. ${ }^{18}$

\section{Discussion}

As one of the most serious long term clinical complica tions of jejuno-ileal bypass, recent reports of a high incidence of cirrhosis on prolonged biopsy follow up (approaching $10 \%$ in some series ${ }^{9}$ ) are clearly of concern to those managing such patients. This is especially important when, as indicated by this study

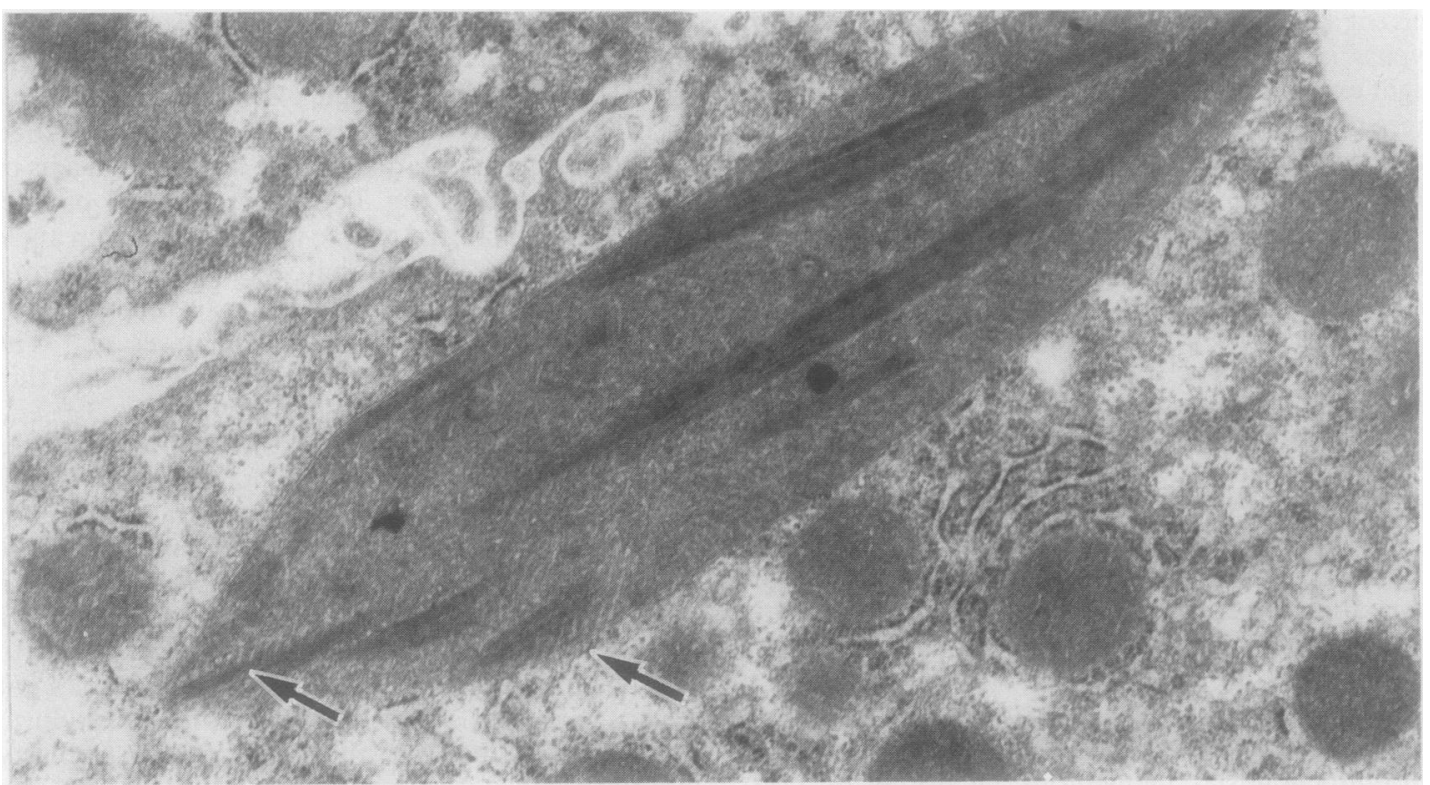

Fig 3 Type II giant mitochondrion containing intramitochondrial filamentous inclusions. Note the $45^{\circ}$ orientation of intramitochondrial filamentous inclusions to mitochondrial cristae (arrows). 


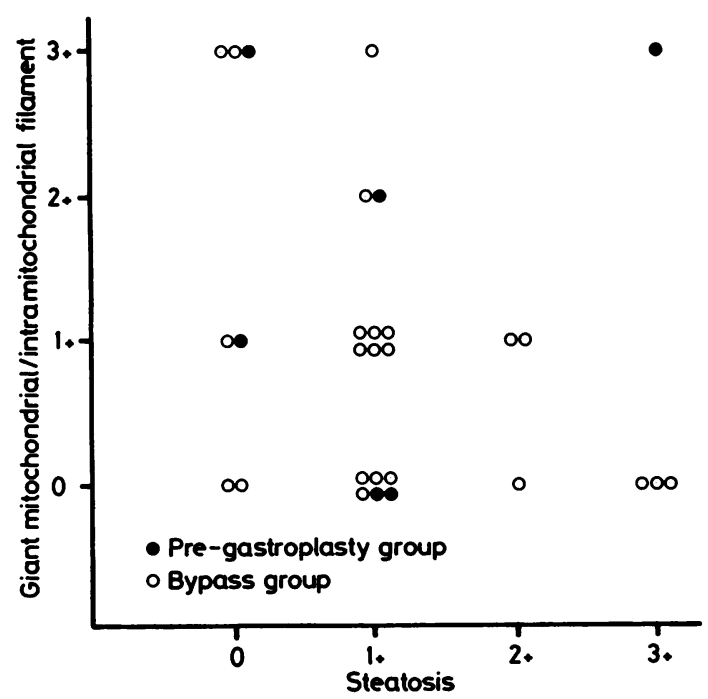

Fig 4 Relation between prevalence of giant mitochondria and intramitochondrial filaments and degree of steatosis within each biopsy specimen.

and many others, ${ }^{12}$ simple biochemical tests of liver function fail to predict abnormalities in morphology. Although our study concerns only a relatively small group of patients and was not designed to determine the true incidence of cirrhosis in long term follow up after jejuno-ileal bypass, there was no evidence of established cirrhosis in any of the specimens examined. Marrubio et al maintain that central pericellular fibrosis in pre-bypass specimens predicts invariable progression, and suggest that this lesion is directly analogous to that seen in alcoholic hepatitis. ${ }^{19}$ In this study four biopsy specimens showed central fibrosis before bypass, albeit to a mild degree. None progressed to severe fibrosis, three showed persistent mild fibrosis, and only one was regarded as moderately fibrotic 11 years after bypass.

Current research strongly suggests that fat-storing or Ito cells have a major role in the insidious fibrosis associated with alcohol damage in experimental animals and some human studies, ${ }^{20}$ transforming under appropriate metabolic conditions into fibroblasts. ${ }^{21}$ As in alcoholic patients, those biopsy specimens showing mild to moderate degrees of fibrosis contained fat-storing cells with increased rough endoplasmic reticulum, indicating probable collagen synthesis. If the fat storing cell does, indeed, act as a facultative fibroblast in patients who have had a jejuno-ileal bypass, it remains unclear which metabolic stress or toxin initiates transformation. A wide range of putative toxins has been suggested, including alcohol production in the excluded bowel segment $^{22}$ and circulating immune complexes, but present theory favours a multifactorial process. ${ }^{23}$ The persistence of steatosis in a high proportion of bypass biopsy specimens may also be interpreted as reflecting a persistently abnormal metabolic environment.

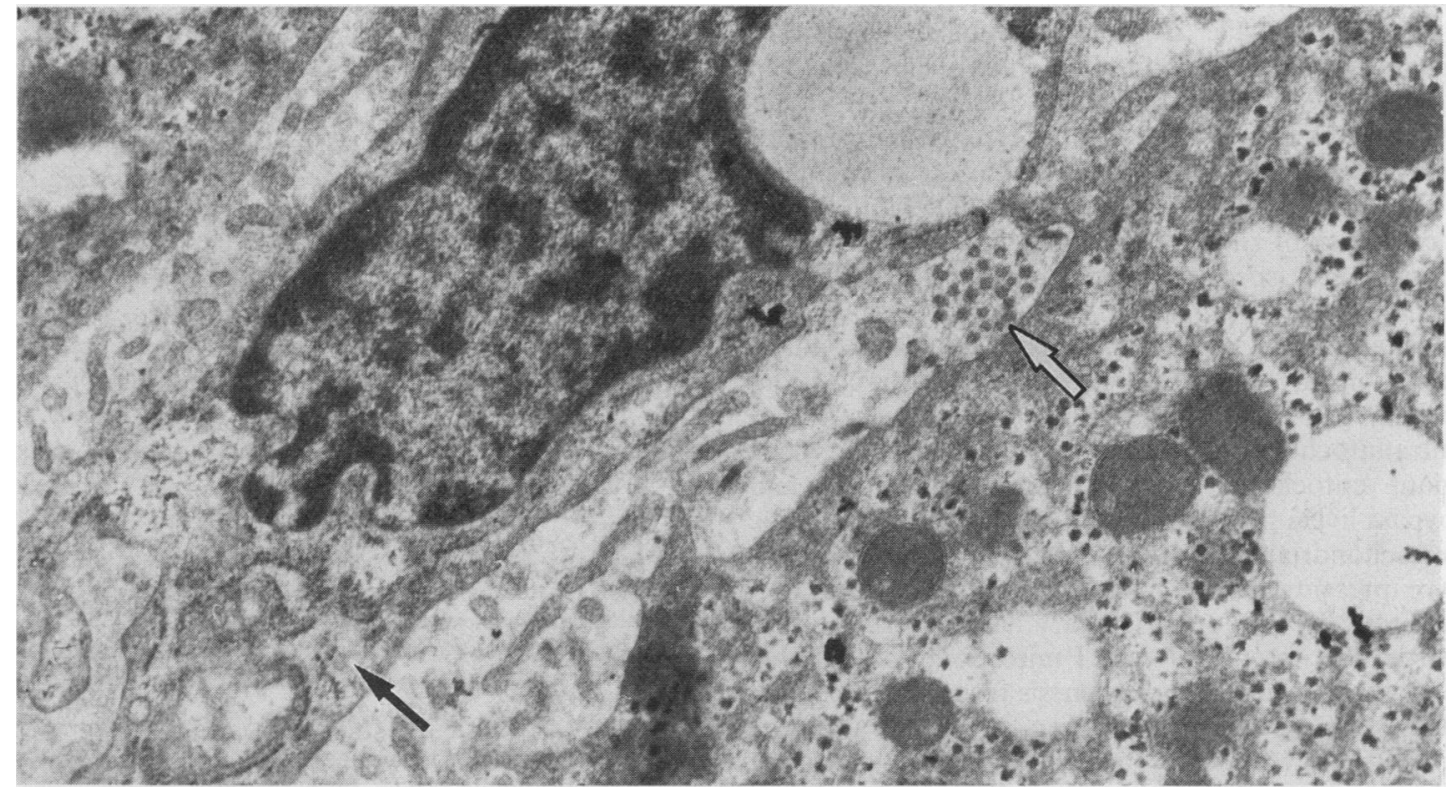

Fig 5 Fat-storing cell showing a moderately well developed rough endoplasmic reticulum (arrow) and collagen within the space of Disse (white arrow). 
Intramitochondrial filamentous inclusions, often occurring in giant mitochondria, have been widely regarded as non-specific degenerative phenomena present in a wide variety of conditions. ${ }^{24}$ Their occurrence in normal subjects is controversial. ${ }^{2526}$ Friedman et al suggest intracellular lipid accumulation as a common factor, ${ }^{13}$ and in a series of biopsy specimens studied soon after bypass, they quantitatively relate the percentage of cytoplasmic surface area containing lipid to the percentage of mitochondria containing filaments. They also maintain that intramitochondrial filamentous inclusions are most prevalent in those biopsy specimens showing moderate steatosis and are less common at the extremes of fat accumulation. We cannot wholly agree with this interpretation. In our study an apparent correlation was shown between moderate or large numbers of giant mitochondria with intramitochondrial filamentous inclusions and little or no steatosis. Furthermore, the correlation within a single biopsy specimen between cytoplasmic lipid content and intramitochondrial filamentous inclusions may simply reflect the preferential accumulation of fat in centrilobular hepatocytes and a tendency of giant mitochondria and intramitochondrial filamentous inclusions to occur in periportal areas. Friedman et al further speculate that mitochondrial abnormalities may eventually resolve following stabilisation of the patients' weight. ${ }^{13}$ This has clearly not occurred in our series.

The commonly held view that intramitochondrial filamentous inclusions and type II giant mitochondria represent organelle "degeneration" may be erroneous. Studies of enzyme activity in such mitochondria seem to indicate normal functioning. ${ }^{17}$ Indeed, Petersen has suggested that they represent hyperfunctioning organelles, preventing the accumulation of excessive lipid. ${ }^{27}$ If so, this would be consistent with our findings. The occurrence of similar structures in a wide variety of organs and species ${ }^{28}$ under appropriate metabolic circumstances suggests a common aetiological mechanism but, as in many aspects of mitochondrial metabolism, ${ }^{29}$ understanding of their composition, origin, and role is incomplete. The occurrence of intramitochondrial filamentous inclusions and type II giant mitochondria in both pre-gastroplasty and bypass livers most probably represents a non-specific mitochondrial adaptation, perhaps reflecting excessive presentation of lipid and immune complexes, respectively. Although O'Leary has suggested otherwise ${ }^{30}$ the absence of type I mitochondria probably indicates a different pathogenesis from alcoholic liver disease where these are common. ${ }^{31}$

Even 10 years after bypass, therefore, persistent abnormalities of hepatic morphology are evident in most patients both on light and electron microscopic examination. Furthermore, ultrastructural changes are common even in biopsy specimens that seem to be normal in conventional histological sections. The prognostic implications are uncertain, and continued regular biopsy follow up of these patients seems advisable.

We are grateful to the staff of the department of histology, General Hospital, Birmingham and in particular Mrs Linda Grosvenor for invaluable technical assistance. We thank Miss Angela Wright for typing the manuscript and the General Hospital Bicentenary Appeal for financial support.

\section{References}

1 Payne JH, DeWind LT. Surgical treatment of obesity. Am J Surg 1969;118:141-7.

2 Maxwell JD, McGouran RC. Jejuno-ileal bypass: clinical and experimental aspects. Scand J Gastroent 1982;74(suppl): 129-47.

3 Jewell WR, Hermreck AS, Hardin CA. Complications of jejunoileal bypass for morbid obesity. Archives of Surgery 1975; 110:1039-42.

4 Payne JH, DeWind LT, Schwat CE, Kern WH. Surgical treatment of morbid obesity. Archives of Surgery 1973;106:432-7.

5 Baddeley RM. Surgical treatment of obesity. Proc $R$ Soc Med 1973;66:1098-9.

6 Peters RL, Gay T, Reynolds TB. Post jejunal bypass hepatic disease. Its similarity to alcoholic hepatic disease. Am J Cli Pathol 1975;63:318-31.

7 Hocking MP, Duerson MC, Alexander RW, Woodward ER. Late hepatic histopathology after jejuno-ileal bypass for morbis obesity. Am J Surg 1981;141:159-63.

8 Allam C, Bala'a M, Shamma'a M. Evolution of liver disease in morbid obesity after small-intestinal bypass and its restoration. Arch Pathol Lab Med 1983;107:195-8.

9 Hocking MP, Duerson MC, O'Leary JP, Woodward ER. Jejunoileal bypass for morbid obesity: late follow-up in 100 cases. N Engl J Med 1983;308:995-9.

10 Griffen WO, Bivins BA, Bell RM. The decline and fall of the jejuno-ileal bypass. Surg Gynaecol Obst 1983;157:301-8.

11 Baddeley RM. The changing shape of obesity surgery. The Practitioner 1983;227:650-7.

12 Drenick EF, Simmons F, Murphy JF. Effect on hepatic morphology of treatment of obesity by fasting, reducing diets and small-bowel bypass. $N$ Engl J Med 1970;282:829-34.

13 Friedman HL, Chandler JG, Nemeth TJ. Hepatic intra-mitochondrial filaments in morbidly obese patients undergoing intestinal bypass. Gastroenterol 1977;73:1353-61.

14 Anderson T, Gluud C. Liver morphology in morbid obesity: a literature study. Int J Obesity 1984;8:97-106.

15 Baddeley RM. The management of gross refractory obesity by jejuno-ileal bypass. Br J Surg 1979;66:525-32.

16 DeWind LT, Payne JH. Intestinal bypass surgery for morbid obesity. JAMA 1976;236:2298-301.

17 Uchida T, Kronborg I, Peters RL. Giant mitochondria in the alcoholic liver diseases-their identification, frequency and pathologic significance. Liver 1984;4:29-38.

18 Minato Y, Hasumura Y, Takeuchi J. The role of fat-storing cells in Disse space fibrogenesis in alcoholic liver disease. Hepatology 1983;4:559-66.

19 Marubbio AT, Rucker RD, Schneider PD, Horstmann JP, Varco RL, Buchwald $H$. The liver in morbid obesity and following bypass surgery for obesity. In: Buchwald $\mathrm{H}$, ed. The surgical clinics of North America 59. No 6. Philadelphia: WB Saunders, 1979:1079-93. 
20 Popper $\mathbf{H}$, Lieber CS. Histogenesis of alcoholic fibrosis and cirrhosis in the baboon. Am J Pathol 1980;98:695-715.

21 McGee JO'D, Patrick RS. The role of perisinusoidal cells in hepatic fibrogenesis. Lab Invest 1972;26:429-40.

22 Mezey E, Imbembo AL, Potter JJ, Rent KC, Lombardo R, Holt PR. Endogenous ethanol production and hepatic disease following jejuno-ileal bypass for morbid obesity. Am J Clin Nutr 1975;28:1277-83.

23 Maxwell JD. Intestinal bypass and the liver. In: Maxwell JD, Gazet JO, Pilkington TR, eds. Surgical management of obesity. London: Academic Press, 1980:235-55.

24 Ghadially FN. Ultrastructural pathology of the cell and matrix. 2nd ed. London: Butterworths, 1982.

25 Wills EJ. Crystalline inclusions in the mitochondria of normal human liver parenchymal cells. J Cell Biol 1965;24:511-4.

26 Bhagwat AG, Ross RC. Hepatic intramitochondrial crystalloids. Archives of Pathology 1971;91:70-7.
27 Petersen P. Abnormal mitochondria in hepatocytes in human fatty liver. Acta Pathol Microbiol Scand (Sect A) 1977;85:413-20.

28 Nunez EA, Greif RL, Gershan MD. Paracrystalloids from mitochondria in thyroid follicular cells. Lab Invest 1975;33: 352-62.

29 Wagner BM. Mitochondrial traffic problems. Hum Pathol 1986; 17:329.

30 O'Leary JP. Hepatic complications of jejuno-ileal bypass. Seminars In Liver Disease 1983;3:203-15.

31 Junge J, Horn T, Christoffersen P. Megamitochondria as a diagnostic marker for alcohol induced centrilobular and periportal fibrosis in the liver. Virchows Arch A 1987;410:553-8.

Requests for reprints to: Dr A P Boon, Department of Pathology, Medical School, University of Birmingham, Birmingham B15 2TJ, England. 